\title{
To Study for the Different Dimensions of Measurement of the Bending and Connecter Losses in Optical Fiber
}

\author{
Prof. B.N.Havaraddi, \\ Department of Physics, K. L. E. Society's B. K. College, Chikodi, Karnataka, India
}

\section{Introduction}

Communication has always dreamt of higher information bandwidth for wires and coaxial lines with frequency available for transmission extends from $10^{8}$ to $10^{9} \mathrm{~Hz}$. But modulated lighth transmission frequency about $10^{10} \mathrm{~Hz}$ range, thus here increase in several orders of magnitude in potential bandwidth is possible. The main drawback these communication systems using the light signal is unguided and it is transmitted through atmosphere where it is subject to attenuation and distortion. Therefore, a better light wave communication system would certainly need a light guide to help preserve the signal and increase the relability and distance of transmission.

However, it was not until like a practical wave guide unnvisaged. This guide was a solid cylinder capable of guiding a wide range of electromagnetic waves including the upper limits of visible light. Another light guide developed during that consist of a hollow tube with a highly reflective metal coating with its inner surface. Thus light injected into one end of either guide bounced back and forth along the length to exit at the other end. These devices had high signal loss and hence, were not much practical use. With some success therein by 1950's these glass fiber bundles were used as light conducts reader for this time the core with its high refractive index and surrounded by that had a lower refractive index.

\section{Theory}

When the light propogated from one end to the other end in single mode or multimode fibre is known called attenuation. Thus attenuation is ratio of optical output power[ $\left.\mathrm{P}_{\text {out }}\right]$ from a fibre of length[ $\mathrm{L}]$ to the input power $\left[\mathrm{P}_{\mathrm{in}}\right]$,

The power loss is given by

$$
=-10 \log \left\{\mathrm{P}_{\text {out }} / / \mathrm{p}_{\text {in }}\right] \quad-----\quad \text { in } \mathrm{dB}
$$

Attenuation $[\mathrm{A}]=$ Power losss/fibre length

$$
\mathrm{A}=-10 \log \left[\mathrm{P}_{\text {out }} / \mathrm{P}_{\text {in }}\right] \times \mathrm{L}
$$

$$
\mathrm{P}_{\text {out }}=\mathrm{P}_{\text {in }} \times 10-\mathrm{A} \times \mathrm{L} / 10
$$

$\mathrm{L}=10 / \mathrm{A} \times \log 10\left[\mathrm{P}_{\text {in }} / \mathrm{P}_{\text {out }}\right]$

Where $\mathrm{P}_{\text {out }}$ and $\mathrm{P}_{\text {in }}$ watts, $\mathrm{L}$ is in $\mathrm{km}$.

\begin{abstract}
Absorption losses
Impurity absorb the light and it convert to heat. Ther are contributes few facters. By atomic defect, impurity atoms basic constutient atoms.

Altra violet absorption is light ionizes the valency electrons in to conduction.This ionization contributes to the trasmition losses. And infrared is photons of light are absorbed but the core molecules these are converted in to random mechanical vibrations. Then ion resonance is caused by $\mathrm{OH}$-ions in the material.
\end{abstract}

\section{Scattering losses.}

It due to impurity particle scattering occours in core or clading. The particle will scatter another direction this effect is total internal reflecton at the boundary of core-clading.This will create loss in the amount of light.

\section{Bending losses.}

Reduction in optical power due to fibre bending knwon as bending losses. This is coused by macroscopic and microscopic mechanisums. Macrascopic is a large scale bend, When a fibre is bent through a large angle know strain is placed along the regions it causes the change in refractive index and in critical angle, as a result losses occur, but it minimum loss. Then micro bends are repetitive small scale ,fluation in the radius of the optical axis. To prevent by losses extruding a common possible jaket over the fibre. Thus jaket will be deformed but the fibre will tend to stray relativily straight. When optical energy travels along 
a fibre due to intra and intermodal. It creates distration for both digital and anolog transmission. To avoid it the digital bit rate must be less than the reciprocal of the broadening pulse duration

\section{Intermodal Dispertion}

Pulse speding within a single mode arrise from finite spectral emission width of the optical source . Since it depends on wavelengh and effect on signle distration increse with spectral width. Then propogation delay difference between different modes.

\section{Intramodal Dispertion}

It take place due to the fact that optical sources do not emitt a single frequancy but a bend of frequancies .This kind of pulse broadening in almost every type of optical fibre . When the disperssive charactaristics of the waveguide material responsible for the delay differencs knwon as material dispersion. Propogation chararaistics are effectted byseveral facters including stransmittance properies the quality of reflecting interface ,residul light leakage through the coating various end losses. These losses in transimission could be divided into lines losses.
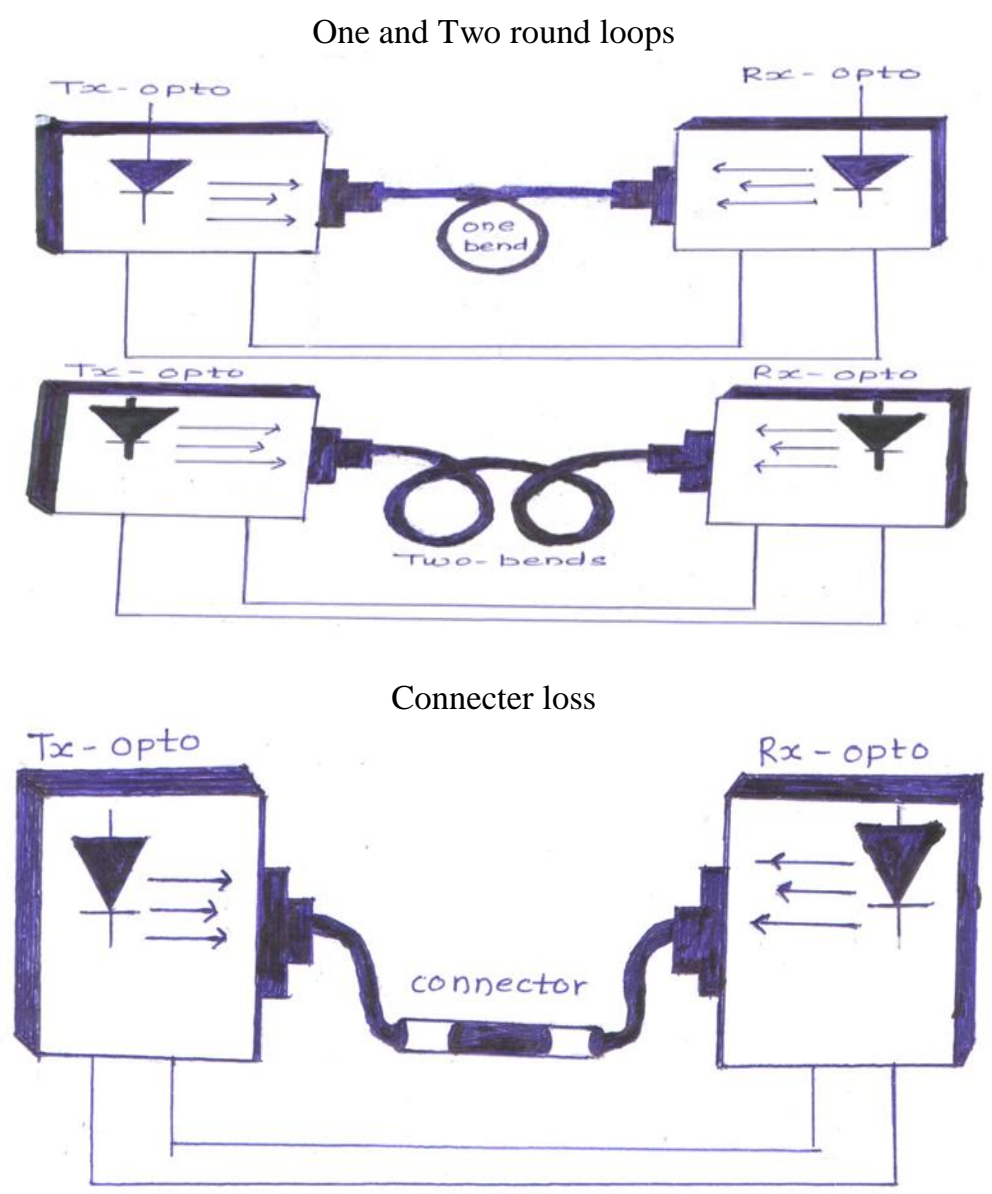

[1] Bending losses.

\section{Procedure}

- Connect the power supply cable at the power in connecter.

- Connect 1 meter optical cable is connect to the TX-OPTO and other end of the fibre cable loop it around one bend connect to the RX-OPTO connecter.

- Put the switch $\mathrm{SW}_{2}$ in the meter position.

- Then switch on the power supply.

- $\quad$ Adjust the intensity knob till the meter reading till $-2.0 \mathrm{~dB}$.

- Swith off the power supply without distrubing the knob position.

- Take the posion of the fibre and loop it around first bend,

- Note down the meter reading in power $-\mathrm{dB}$. Then fiber loop it around two bends then connect again, note down again meter reading in- $\mathrm{dB}$. 
[2] Connecter loss.

- Priminary adjustments similar previous steps,

- Now connect one end fiber cable about 2 meter length to TX-OPTO other end to connecter, connect one end of 1 meter cable to RX-OPTO and other end to the connecter.

- The connecter the two cables must be placed in properly the ends without any gap. Then connecter loss can be calculated.

\begin{tabular}{|c|c|c|c|c|c|c|c|c|c|}
\hline \multirow{2}{*}{$\begin{array}{l}\text { Sl } \\
\text { No } \\
\end{array}$} & \multirow{2}{*}{$\begin{array}{l}\text { Size of the } \\
\text { fiber }\end{array}$} & \multirow{2}{*}{$\begin{array}{l}\text { Lengh of } \\
\text { the fiber }\end{array}$} & \multicolumn{7}{|c|}{ Meter Readings } \\
\hline & & & $\begin{array}{l}\text { Withouth } \\
\text { Bending or } \\
\text { connecter }\end{array}$ & $\begin{array}{l}\text { One } \\
\text { round } \\
\text { bending }\end{array}$ & $\begin{array}{l}\text { Two } \\
\text { rounds } \\
\text { bending }\end{array}$ & $\begin{array}{l}\text { Loss in } \\
\text { One } \\
\text { round }\end{array}$ & $\begin{array}{l}\text { Loss in } \\
\text { Two } \\
\text { bending }\end{array}$ & $\begin{array}{l}\text { Loss in } \\
\text { One } \\
\text { connecter }\end{array}$ & $\begin{array}{l}\text { Loss in } \\
\text { connecter }\end{array}$ \\
\hline \multirow[t]{3}{*}{1} & 1', diameter & 1meter & $-6.0 \mathrm{~dB}$ & $-3.1 d B$ & $-2.6 \mathrm{~dB}$ & $2.9 \mathrm{~dB}$ & 3.4dB & $-9.8 \mathrm{~dB}$ & $3.8 \mathrm{~dB}$ \\
\hline & 1.5' diameter & 1meter & $-6.0 \mathrm{~dB}$ & $-3.4 \mathrm{~dB}$ & $-2.3 \mathrm{~dB}$ & $2.6 \mathrm{~dB}$ & $3.7 \mathrm{~dB}$ & $-9.3 \mathrm{~dB}$ & $3.36 \mathrm{~dB}$ \\
\hline & 2.0 diameter & 1meter & $-6.0 \mathrm{~dB}$ & $-3.5 \mathrm{~dB}$ & $-2.8 d b$ & $2.5 \mathrm{db}$ & $3.2 \mathrm{~dB}$ & $-8.9 \mathrm{~dB}$ & $2.9 \mathrm{~dB}$ \\
\hline \multirow[t]{3}{*}{2} & 1', diameter & 2meter & $-6.0 \mathrm{~dB}$ & $-3.3 \mathrm{~dB}$ & $-2.5 \mathrm{~dB}$ & $2.7 \mathrm{~dB}$ & $3.5 \mathrm{~dB}$ & $-9.0 \mathrm{~dB}$ & 3.0dB \\
\hline & 1.5' diameter & 2meter & $-6.0 \mathrm{~dB}$ & $-3.5 \mathrm{~dB}$ & $-2.2 \mathrm{~dB}$ & $2.5 \mathrm{~dB}$ & 3.8dB & $-8.8 \mathrm{~dB}$ & $2.8 \mathrm{~dB}$ \\
\hline & 2.0 'Diameter & 2meter & $-6.0 \mathrm{~dB}$ & $-3.4 \mathrm{~dB}$ & $-2.7 \mathrm{~dB}$ & $2.6 \mathrm{~dB}$ & 3.4dB & $-8.9 \mathrm{~dB}$ & $2.9 \mathrm{~dB}$ \\
\hline \multirow[t]{3}{*}{3} & 1', diameter & 3meter & $-6.0 \mathrm{~dB}$ & $-3.8 d B$ & $-2.8 d B$ & $2.2 \mathrm{~dB}$ & $3.2 \mathrm{~dB}$ & $-9.0 \mathrm{~dB}$ & 3.0dB \\
\hline & 1.5" diameter & 3meter & $-6.0 \mathrm{~dB}$ & $-3.5 \mathrm{~dB}$ & $-2.7 d B$ & $2.5 \mathrm{~dB}$ & $3.3 \mathrm{~dB}$ & $-8.7 \mathrm{~dB}$ & $2.7 \mathrm{~dB}$ \\
\hline & 2.0 diameter & 3meter & $-6.0 \mathrm{~dB}$ & $-3.4 d B$ & $-2.5 \mathrm{~dB}$ & $2.6 \mathrm{~dB}$ & $3.5 \mathrm{~dB}$ & $-8.5 \mathrm{~dB}$ & $2.5 \mathrm{~dB}$ \\
\hline
\end{tabular}

\section{Conclusions}

The attenuation coefficient is the function of angle of incient, wavelength and type of fiber.The angle of incident increases both the path and number of reflection increse. Therefore attenuation get increaed. This causes the reduction in the effective numerical aperture with the length of the fiber. The coupling light sources to fiber for the trasmission signals, it is necessary to be able to couple.This is the impartance where fiber cable have to be joined to fiber. Loss to be fiber coupling depends on types of joint, size, refractive index, eccentricity of the core, and numerical apertures mechanical misaligmenst, longitudinal, lateral and angular misalignment of the fibers. Then connecter loss can be calculated.

\section{Reference}

[1]. Kapany,N.S., Fibre optics,principle and applications, academic press.Inc.,N.Y.,1967

[2]. (Barnoski,M.K,Fundamental of optical communication academic press,Inc.,N.Y.1976,2 ${ }^{\text {nd }}$ Ed 1982

[3]. Technical staff of CSELT, optical fibre communication.centro studio laboratory Telecomunicazioni.Torino,1980

[4]. Marcuse.D.principle of optical fibre measurements.Academic press,Inc.,N.Y.,

[5]. Cherin.A.H.An Introduction to optical fibres,Mc Graw Hill Bookco.N.Y.,1983

[6]. Sharma,N.,Fibre optics in Telecommunications, Tata Mc Graw Hill Co.,New Delhi,1987,pp.172-173

[7]. Nelson.B Petal.Design and menufactare of optical fibre with specific dispersion characteristics, electronics letters,21(1985),274275.

[8]. Murata.H.Hand book of optical fibres and cables murcel Dekker Inc.N.Y,1988 